\title{
DESAIN TAMAN KULINER UNTUK PEDAGANG KAKI LIMA YANG INOVATIF DI TEPI SUNGAI, SURABAYA
}

\author{
Gunawan Tanuwidjaja ${ }^{1 *}$, El Sadday A. Oktovianto ${ }^{2}$, Joyie $^{3}$, Felicia Lisandra S. ${ }^{4}$ \\ 1,2,3,4 Fakultas Teknik Sipil dan Perencanaan, Program Studi Arsitektur, Universitas Kristen PetraJl. \\ Siwalankerto 121-131, Surabaya 60236 \\ * Penulis korespondensi; Email: gunte@petra.ac.id
}

\begin{abstract}
Abstrak: Dewasa ini, para pemilik Usaha Kecil dan Menengah (UKM) terutama pedagang kaki lima (PKL) yang bergerak di bidang makanan sedang di hadapkan pada sebuah kesulitan dalam meningkatkan skala usaha dan produktivitas. Selain itu PKL masih belum mampu bersaing, di sebabkan oleh masalah keterbatasan desain arsitektur, sumber daya manusia, dan juga strategi pemasaran. Di sisi lain, masyarakat Surabaya yang memiliki kebiasaan untuk berkumpul dan berinteraksi satu dengan yang lain saat menikmati sebuah makanan, tetapi belum tersedia fasilitas PKL yang nyaman. Oleh karena itu, perlu sebuah desain Pusat PKL makanan yang terintegrasi dengan Taman Kota dengan memperhatikan kebersihan, kenyamanan, kerapihan, serta citra positif. Pada karya tulis ini, dipaparkan sebuah proses desain kios PKL, yang diawali dengan ekplorasi ke restoran makanan tradisional dan PKL makanan tradisional dengan metode riset visual. Kedua disusunlah sebuah desain berdasarkan prinsip - prinsip desain inklusi seperti User Centered (Berpusat kepada Pengguna), Equitable use but Reasonable (Penggunaan yang Setara tetapi Masuk Akal), Simple and Intuitive Use (Penggunaan yang Sederhana dan Intuitif), Low Physical Effort (Upaya Fisik yang Rendah) dan Prohibition of Usage Error (Pencegahan terhadap Penggunaan yang Salah).
\end{abstract}

Kata kunci: PKL; desain inklusi; kampung tepi sungai.

\begin{abstract}
Nowadays, the owners of Small and Medium Enterprises (SMEs), especially food street vendors (PKL) faced difficulty to increase the operational scale and productivity. Besides that, the street vendors are still not able to compete, because of limited architectural design, human resources, and marketing strategies. Therefore, street-food center design, which integrated with Urban Park was needed with attention of cleanliness, comfort, neatness aspects and producing positive image. In the paper, design process street-hawker kiosk was started with exploration into traditional food restaurants and traditional food vendors using visual research. The design was based on the principles of inclusive design such as: User Centered, Equitable use but Reasonable, Simple and Intuitive Use, Low Physical Effort, and Prohibition of Usage Error.
\end{abstract}

Keywords: Street vendors, inclusive design, riverside village

\section{PENDAHULUAN}

Dengan adanya Usaha Kecil dan Menegah Ekonomi (UKM), Indonesia mendapatkan kontribusi dalam pengembangan ekonomi menurut Ardiana, dkk. (Ardiana, I.D.K.R., Brahmayanti, I.A., \& Subaedi, Subaedi, 2010). Dalam data Biro Pusat Statistik Indonesia (Biro Pusat Statistik Indonesia, 2004) kontribusi UKM terhadap PDB (tanpa sektor minyak dan gas) terjadi peningkatan dari titik $62,71 \%$ pada tahun $2002-63,89 \%$ saat tahun 2003 . Sementara itu, UKM juga telah mendukung $99,45 \%$ dari tenaga kerja di Indonesia untuk periode 20002003. Terlihat sekali bahwa peran UKM sangat besar terhadap perekonomian di Indonesia.
Di lain sisi, UKM juga menghadapi permasalahan dalam meningkatkan skala usaha, produktivitas dan bersaing secara internasional karena masalah yang timbul pada proses awal sebuah usaha seperti adanya sumber daya manusia dan strategi pemasaran yang terbatas. Utami, \& Lantu (Utami, R.M., \& Lantu, D.C., 2014), berpendapat bahwa “ Daya saing dalam UKM berhubungan dengan potensi, proses, dan kinerja“. Di dalam Aspek Potensi terdapat karakteristik pemilik, karakteristik perusahaan, kemampuan internal dan lingkungan eksternal. Aspek proses terbentuk oleh operasi dan pelaksanaan pertumbuhan yang efektif. Sedangkan dalam Aspek kinerja terdapat kinerja keuangan dan non-keuangan. Oleh karena itu, 
menggunakan strategi pengembangan UKM makanan sangat penting di terapkan di Surabaya dan di daerah yang lain.

Sementara itu, Susanto \& Suparlan (Susanto, D. \& Suparlan, P, 1989). menjelaskan pentingnya Usaha Kecil dan Menengah (UKM) sektor makanan karena mempengaruhi hubungan kelangsungan hidup manusia dan lingkungannya. Proses pengolahan makanan memerlukan: strategi pemberian pakan, produksi pangan, pengolahan makanan dan mengkonsumsi yang pada akhirnya mempengaruhi dan menjaga hubungan antara ekosistem dan budaya manusia dengan baik.

Kemudian, Wirosardjono (Wirosardjono, S., 1976) menjelaskan beberapa ciri dari PKL yang di antaranya ialah:

1. Pola kegiatannya yang tidak teroganisir dalam waktu dan keuangan.

2. Tidak mematuhi peraturan-peraturan atau ketentuan pemerintah.

3. Menggunakan modal, peralatan yang terbatas, dengan pendapatan kecil yang berputar dalam siklus harian

4. Tidak menetap dan tidak terikat dengan usaha lainnya.

5. Dikerjakan oleh masyarakat golongan ekonomi lemah serta melayani golongan tersebut juga.

6. Dapat dikerjakan tanpa keahlian dan ketrampilan khusus sehingga dapat menyerap banyak tenaga kerja.

7. Umumnya memperkerjakan sejumlah kecil tenaga kerja dari lingkungan hubungan keluarga, teman dan daerah asal yang sama.

8. Tidak menerapkan sistim perbankan, pembukuan, perkreditan dan sebagainya.

Pertumbuhan Pedagang Kaki Lima (PKL) khususnya di Surabaya terdapat perkembanganyang sangat pesat pada beberapa wilayah. Hal ini disebabkan oleh kebutuhan masyarakat akan barang - barang yang harganya lebih terjangkau. Barang-barang yang diperlukan oleh para konsumen pun juga disediakan oleh sekitar 50.000 PKL Surabaya. Dengan fakta ini, penanganan dan pendampingan sangat diperlukan untuk meningkatkan kesejahteraan masyarakat dan PKL (http:// www.kabarbisnis.com/read/2836424).

Dinas Koperasi dan Usaha Kecil dan Menengah telah melakukan penaataan di berbagai titik seperti Sentra PKL Gayungan, Urip Sumoharjo, Taman Bungkul, Ketabang Kali, Taman Prestasi, Ikan Hias Gunungsari, Benowo, Bulak, dan Karah. Konsep penataan PKL yang telah diusulkan Dinkop UMKM antara lain ialah (http://rujak.org/2013/07/ penataan-pkl-solo-bandung-surabaya-dan-angkok/);
A. Penetapan:

1. Penetapan dan pengaturan waktu kegiatan usaha PKL

2. Penetapan dan pengaturan jumlah PKL pada setiap lokasi PKL

3. Penetapan jenis barang yang diperdagangkan

4. Pengaturan alat peraga (perlengkapan PKL seperti gerobak, dll)

B. Pemindahan lokasi

C. Penghapusan lokasi

D. Pemberdayaan PKL:

1. Bimbingan dan penyuluhan manajemen usaha

2. Pengembangan usaha melalui kemitraan dengan pelaku ekonomi yang lain

3. Bimbingan untuk memperoleh dan meningkatkan permodalan

4. Peningkatan kualitas alat peraga PKL

Sementara itu salah bukti penataan PKL ini yang berhasil ialah Sentra PKL Taman Bungkul. Penataan PKL Taman Bungkul ini bertujuan untuk penataan taman, makam, dan pemberdayaan sektor informal. Pada tahun 1999, diadakan penertiban dari Pemerintah Kota dan pembentukan Paguyuban PKL yang bernama Paguyuban Trisula. Lokasi PKL kemudian ditata untuk sentra PKL. Status PKL Taman Bungkul kemudian dibina oleh Pemerintah Kota Surabaya sejak tahun 2005. Saat ini pengunjung Taman Bungkul dan Pusat PKL ini semakin meningkat. Karena itulah nampaknya desain taman kuliner dapat merupakan usulan yang nyata untuk mengatasi masalah PKL sekaligus meningkatkan kualitas ruang terbuka hijau di dalam Kota (http://www-edc.eng.cam.ac.uk/betterdesign).

\section{STUDI LITERATUR}

Inclusive design atau desain inklusi merupakan proses pembelajaran dalam rancangan produk dan/ atau jasa yang dapat diakses, dan digunakan oleh orang banyak secara wajar. Pendekatan yang holistik dan adaptif juga diberikan dalam proses pembelajaran dan pengaplikasian sebuah rancangan atau desain. Selain itu desain inklusi juga memfasilitasi berbagai orang dari berbagai usia, gender, kemampuan dan kondisi, dengan menghilangkan hambatan dalam hal sosial, teknik, politik dan proses ekonomi menurut Ormerod \& Newton (Ormerod, M., \& Newton, R., 2003).

Sehingga desain inklusi juga harus memfasilitasi setiap penggunanya dengan berbagai latar belakang sosial-ekonomi seperti halnya PKL yang ada di Surabaya ini. Kemudian lima prinsip menurut Tanuwidjaja (Tanuwidjaja, Gunawan, 2014), yang dijadikan sebagai acuan desain yaitu: 
1. User Centered (Berpusat kepada Pengguna)

2. Equitable use but Reasonable (Penggunaan yang Setara tetapi Masuk Akal)

3. Simple and Intuitive Use (Penggunaan yang Sederhana dan Intuitif)

4. Low Physical Effort (Upaya Fisik yang Rendah)

5. Prohibition of Usage Error (Pencegahan terhadap Penggunaan yang Salah)

Dengan penerapan lima prinsip ini diharapkan agar desain PKL ini menjadi lebih menarik, aman dan mudah diakses oleh semua golongan pengunjung.

Taman kota menurut Shirvani (Shirvani, H, 1985) merupakan Elemen Urban Design yang penting karena akan menjadi Activity Support dari Kota yang Berkelanjutan. Sehingga jika diintegrasikan dengan Pusat PKL maka akan meningkatkan keberlanjutan Pusat PKL karena menarik banyaknya pengunjung ke tempat tersebut. Karena itulah maka idealnya Pusat PKL harus terintegrasi dengan Taman Kota yang dapat diakses oleh kendaraan umum, kendaraan pribadi, memiliki parkir yang memadai dan didesain dengan indah.

\section{METODOLOGI}

Melalui beberapa hasil riset yang dilakukan, sehingga dapat menghasilkan karya desain bagi PKL yang berjudul Capturing The Family Buiness Resilience in Traditional Food Sector in Surabaya (Mendokumentasikan Ketahanan Bisnis Keluarga di Sektor Makanan Tradisional di Surabaya). Karya desain ini mendapat dukungan dari pihak UNDK (University Network of Digital [Local] Knowledge) (http://undk.asia) dan sekaligus dukungan pendanaan oleh United Boards. (http://unitedboard.org/)

Riset yang dilakukan ialah dengan eksplorasi oleh metode riset visual berdasarkan Sanoff (Sanoff, H., 1991), dimana riset tersebut dilakukan pada restoran Bandar Jakarta di Surabaya Barat sebagai restoran makanan tradisional dan PKL makanan laut yang berada di tepi sungai di Surabaya yang difasilitasi oleh Paguyuban Warga Strenkali Surabaya sebagai PKL makanan tradisional.

Hasil riset inilah yang menjadi pedoman bagi rancangan desain PKL di Jalan Gunung Sari, Joyoboyo, Surabaya (Bersebelahan dengan Monumen Ronggolawe). Selain melakukan eksplorasi, workshop desain dengan para PKL juga dilakukan dan setelah itu akan dilanjutkan dengan penyempurnaan desain sehingga sebisa mungkin dapat diterapkan di kawasan Joyoboyo tersebut.

Pada kawasan ini terlihat jumlah PKL yang cukup minim di sekitar taman dan monumen Ronggolawe.
Namun potensi para PKL cukup tinggi untuk berjualan di sekitar kawasan ini. Dengan melihat peluang ini, rencana perancangan desain kios PKL akan menggunakan kawasan ini, lebih tepatnya pada area taman dekat dengan monumen Ronggolawe.

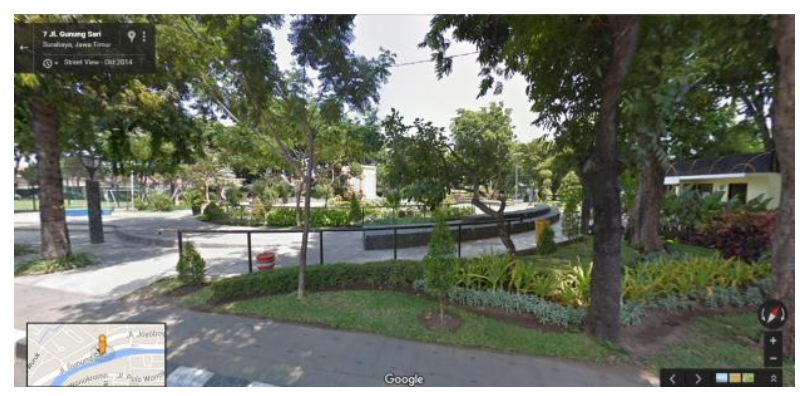

Gambar 1. Lokasi Taman Monumen Ronggolawe yang akan diintegrasikan dengan Pusat PKL (Sumber: Googlemap)

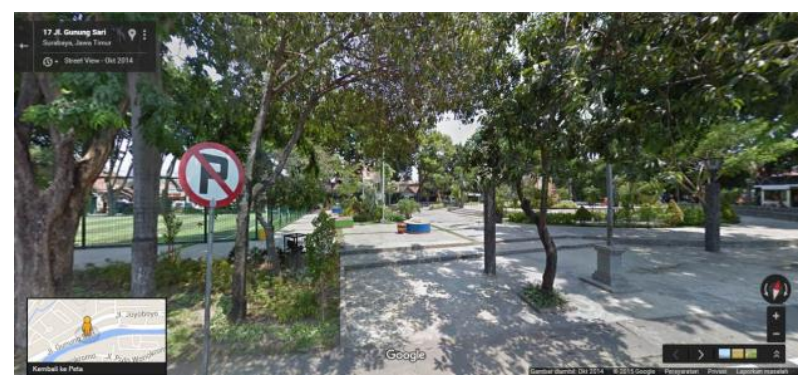

Gambar 2. Suasana Taman Kota yang akan diintegrasikan dengan Pusat PKL (Sumber: Googlemap)

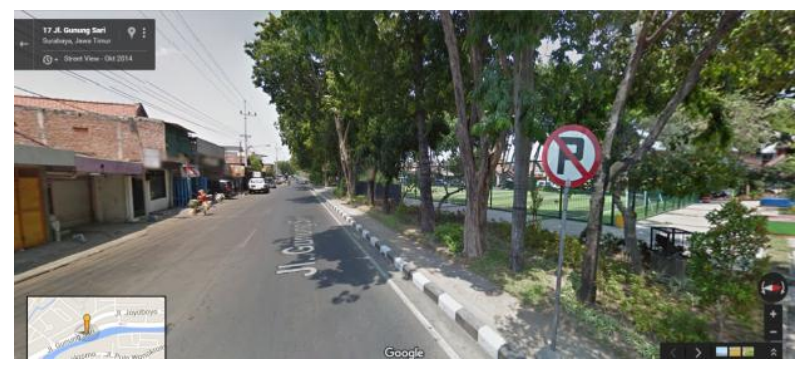

Gambar 3. Akses kendaraan pribadi dan umum yang dapat meningkatkan keberlanjutan Pusat PKL ini (Sumber: Googlemap)

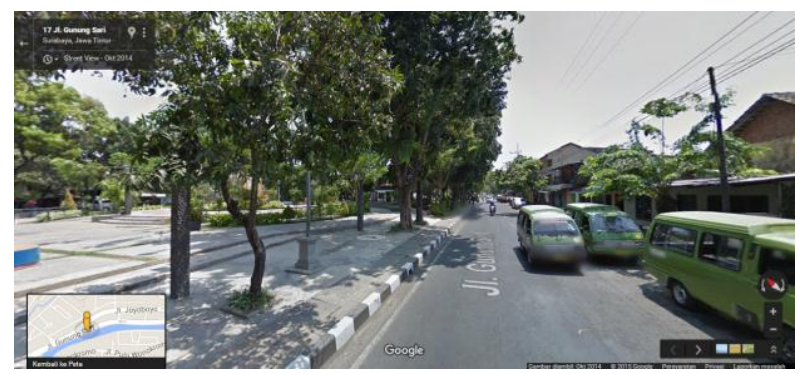

Gambar 4. Akses kendaraan pribadi dan umum yang dapat meningkatkan keberlanjutan Pusat PKL ini (Sumber: Googlemap) 
Sebuah Workshop diadakan pada April 2016 untuk membicarakan desain ini dengan PKL yang ada di sekeliling kawasan tersebut. Hal ini mendapatkan sambutan yang baik. Tetapi ide ini masih perlu disempurnakan dengan diskusi bersama Pemerintah Kota sebelum diterapkan dalam skala yang sebenarnya.

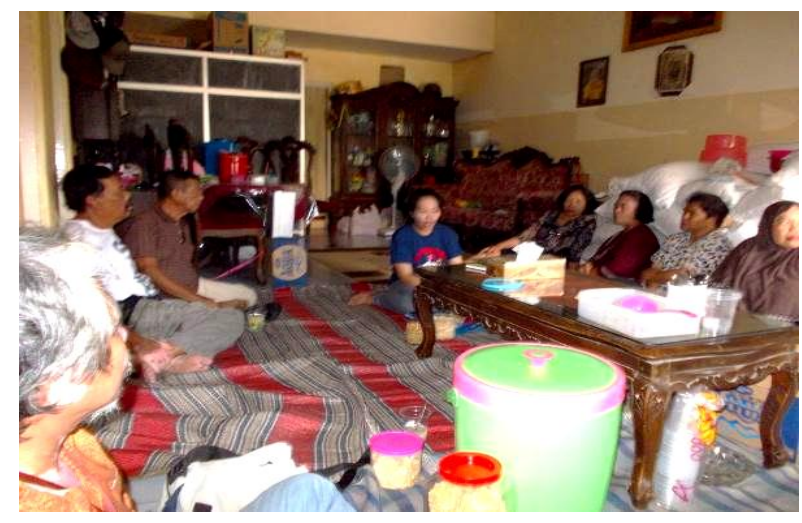

Gambar 5. Diskusi Desain Pusat PKL dengan para warga di tempat

\section{HASIL DAN PEMBAHASAN}

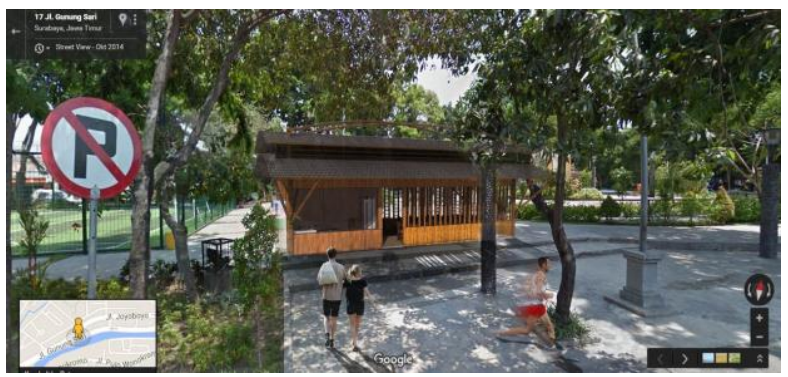

Gambar 6. Gambar Taman Kota yang terintegrasi dengan Pusat PKL (Sumber: Googlemap, dengan Modifikasi Penulis)

Dengan pertimbangan lokasi dan lingkungan sekitar, perancangan desain kios PKL berada pada area kosong bersebelahan dengan monumen Ronggolawe. Dapat terlihat desain kios PKL memiliki akses langsung dari jalan raya Gunung Sari dan dari taman. Dengan ide konsep semi terbuka, kios ini dapat memaksimalkan view taman yang indah dan pengunjung juga dapat melihat keramaian kios yang menarik.

Dalam Taman Kota ini akan diiisi oleh 5 bangunan PKL seperti di atas sehingga akhirnya bisa dijadikan Pusat Wisata Kuliner sesuai dengan usulan Pemerintah Kota Surabaya dan menjawab kebutuhan PKL setempat.

Kemudian dalam sebuah masa PKL akan didesain lebih detail sebagai berikut: Kios PKL diasumsikan akan digunakan oleh PKL makanan laut sehingga dibagi zoningnya menjadi 2 bagian, yaitu area basah yang digunakan untuk memasak dan toilet (ditandai dengan warna biru), yang kedua ialah area kering sebagai ruang makan (ditandai dengan warna merah). Pembagian zoning dapat dilihat dengan adanya dinding sebagai batasan, hal ini bertujuan agar daerah dapat terlihat lebih bersih dan tertata rapi. Hal ini merupakan penerapan dari prinsip ketiga yaitu Simple and Intuitive Use (Penggunaan yang Sederhana dan Intuitif).

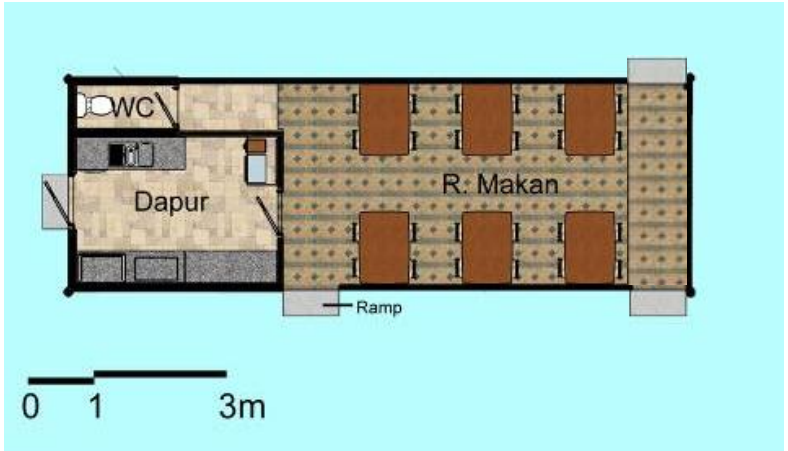

Gambar 7. Denah PKL untuk Hidangan Laut

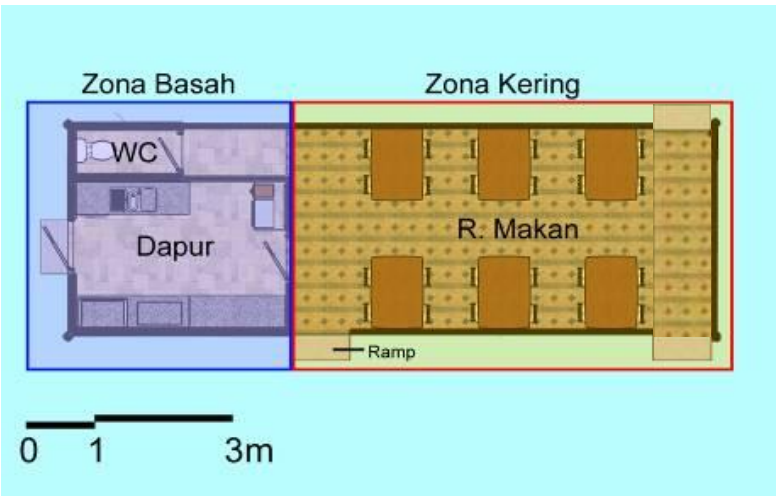

Gambar 8. Pembagian zoning pada denah PKL. Denah PKL untuk Hidangan Laut yang dibagi dengan Zoning Basah dan Zoning Kering

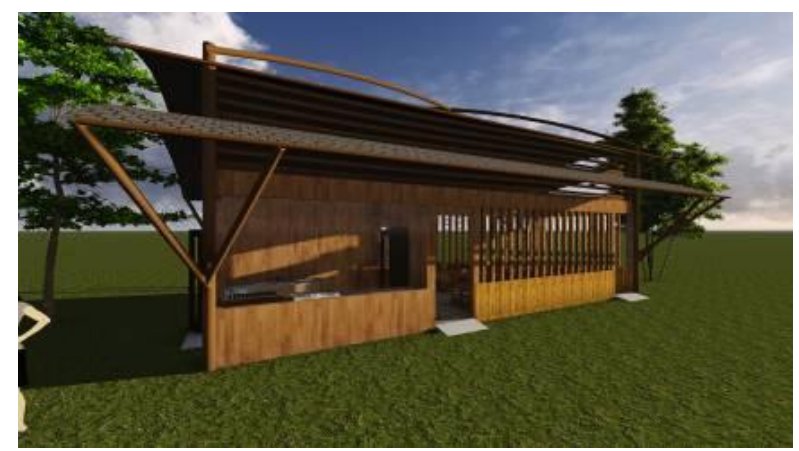

Gambar 9. Penambahan ramp yang berfungsi untuk mempermudah akses bagi trolley dan pengguna kursi roda atau Stroller

Sebagai jalur sirkulasi, desain PKL ini menggunakan ramp dengan tujuan agar mempermudah akses keluar masuk bagi pegawai yang membawa trolley 
serta bagi pengguna kursi roda dan trolley bayi. Prinsip ini diterapkan berdasarkan Prinsip ke-2 Equitable use but Reasonable (Penggunaan yang Setara tetapi Masuk Akal) dan Prinsip ke-4 Low Physical Effort (Upaya Fisik yang Rendah) yang bertujuan agar suatu desain dapat diakomodasikan oleh pengguna dalam keadaan apapun.

Penerapan prinsip ke-5 Prohibition of Usage Error (Pencegahan terhadap penggunaan yang salah) ialah dengan menggunakan material lantai berupa keramik anti-slip yang bertujuan agar tidak terjadi kecelakaan oleh pengguna bangunan. Penggunaan material ini didasarkan atas penggunaan keramik anti-slip di dapur Bandar Djakarta.

Prinsip ke 2. Equitable use but Reasonable (Penggunaan yang Setara tetapi Masuk Akal) juga dilakukan dengan dengan penataan meja yang dapat menyediakan ruang yang memadai di selasar bagi pengguna kursi roda.

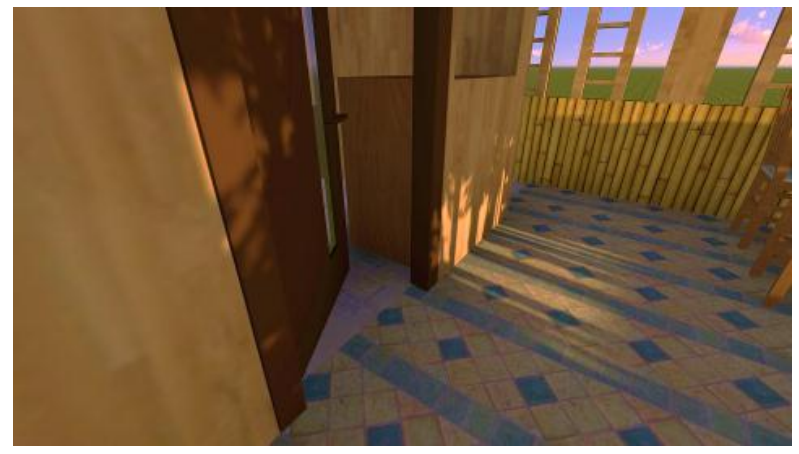

Gambar 10. Perbedaan jenis keramik yang digunakan pada ruang makan dan dapur

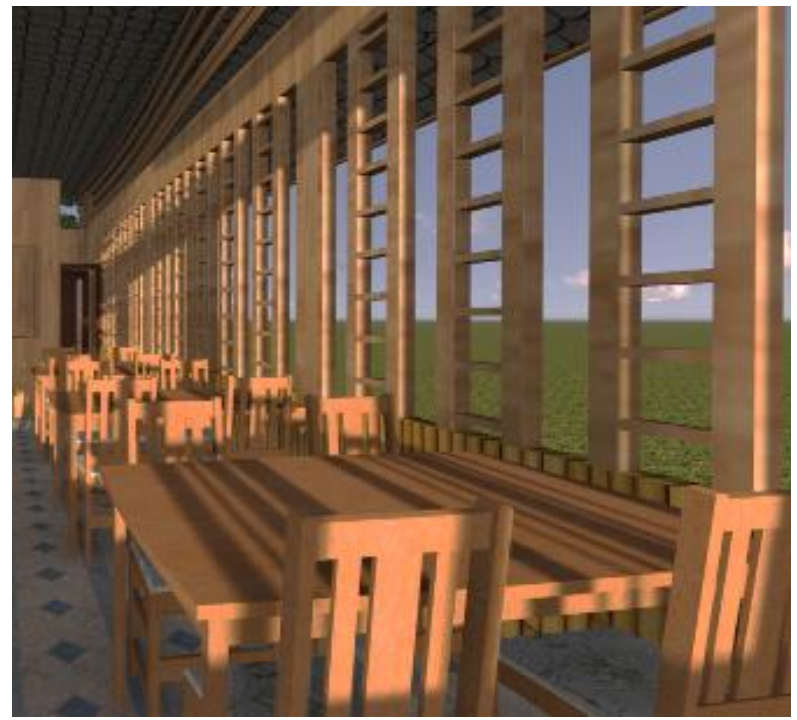

Gambar 11. Jendela kayu pada bangunan yang berfungsi sebagai cross ventilation

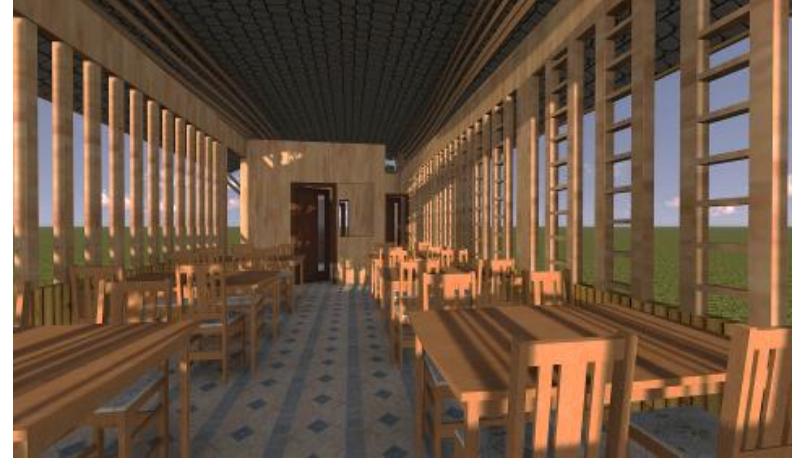

Gambar 12. Selasar pada ruang makan, yang berfungsi untuk sirkulasi bagi pengguna kursi roda

Material yang digunakan bagi selubung bangunan ialah dengan menggunakan kayu dan bambu sebagai upaya penerapan cross ventilation. Pemilihan material ini didasarkan pada material kayu dan bambu yang mudah didapatkan di indonesia dan pori-pori pada material tersebut yang memungkinkan adanya penghawaan alami yang masuk. Kemudian material ini diawetkan agar menimbulkan karakter rumah makan tradisional.

Sebagai suatu bangunan yang berfungsi sebagai tempat memasak, maka untuk menunjang kenyaman pengguna bangunan yaitu dengan penggunaan desain atap yang lebih tinggi (stack effect) yang bertujuan untuk sirkulasi udara yang lebih baik khususnya untuk area dapur yang banyak menghasilkan asap sehingga pertukaran udara di dalam bangunan tidak hanya melalui cross ventilation.

Untuk menunjang penggunaan material kayu dan bambu, maka pada bagian atap juga ditambahkan dengan adanya sosoran (canopy) yang mengelilingi bangunan, bertujuan sebagai tampias air hujan dan sinar matahari secara langsung. Hal tersebut juga akan berdampak bagi kenyamanan pengguna bangunan.

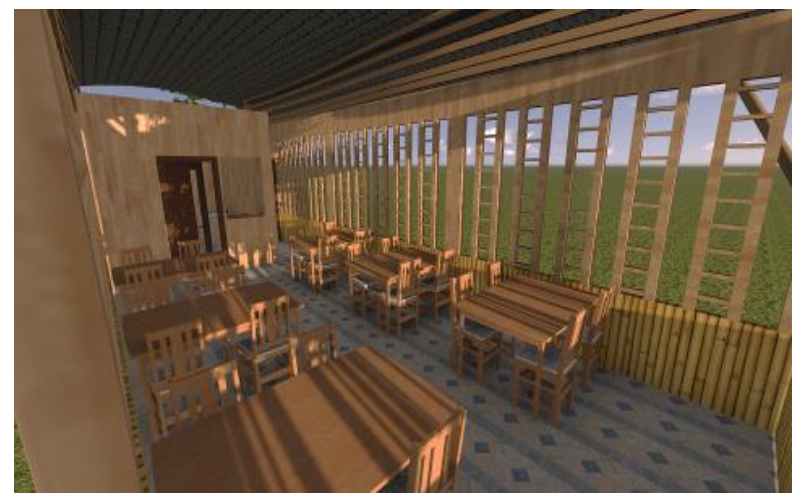

Gambar 13. Sistem Stack Effect yang diterapkan pada atap bangunan 


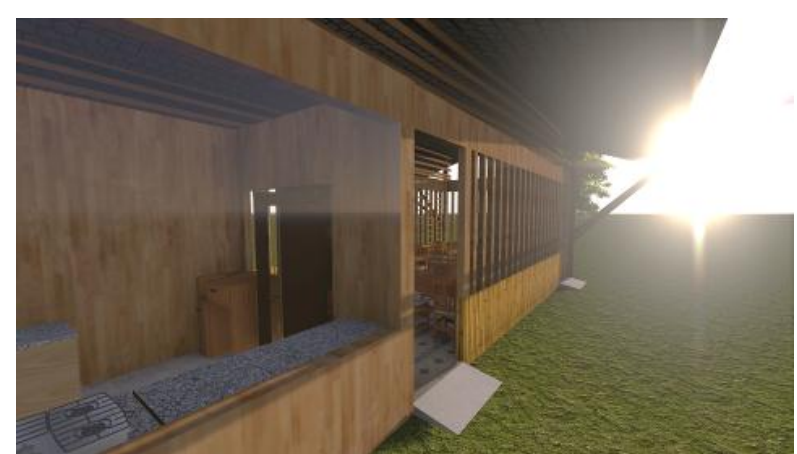

Gambar 14. Penggunaan Canopy dengan tujuan untuk tampias air hujan dan penghalang radiasi matahari secara langsung

\section{KESIMPULAN}

Setelah melakukan berbagai metode untuk mendapatkan desain bagi para PKL yang didasari oleh prinsip desain inklusi, maka dapat disimpulkan beberapa aspek penting dan penerapannya kedalam desain yang universal. Beberapa prinsip tersebut ialah User Centered (Berpusat kepada Pengguna), Equitable use but Reasonable (Penggunaan yang Setara tetapi Masuk Akal), Simple and Intuitive Use (Penggunaan yang Sederhana dan Intuitif), Low Physical Effort (Upaya Fisik yang Rendah), dan Prohibition of Usage Error (Pencegahan terhadap Penggunaan yang Salah). Tetapi memang diakui beberapa bagian ruang dalam Dapur dan WC tidak dapat memenuhi beberapa prinsip yaitu Equitable use but Reasonable (Penggunaan yang Setara tetapi Masuk Akal) karena keterbatasan luasan PKL yang ada dan dana untuk renovasi ini.

Selain itu upaya untuk meningkatkan kenyamanan ialah dengan rancangan atap yang lebih tinggi (stack effect) dan penggunaan material kayu dan bambu. Kedua hal tersebut dapat menunjang adanya penghawaan yang bagus bagi penggna didalamnya. Selain itu tujuan dari pemilihan material tersebut ialah untuk memberikan karakter tradisional pada bangunan. Oleh karena itu dengan segala upaya yang telah dilakukan, diharapkan agar rancangan bagi PKL ini dapat benar-benar terwujud dan digunakan dengan maksimal secara universal.

\section{UCAPAN TERIMA KASIH}

Ucapan terimakasih diberikan kepada:

- United Boards

- UNDK Indonesia

- Wakil Rektor Bidang Akademik UK Petra, Bapak Prof. Dr. Ir. Djwantoro Hardjito, M.Eng.

- Ketua LPPM UK Petra dan Board of Director UNDK di Petra, Ibu Dr. Juliana Anggono, S.T., M.Sc.
- Ketua Program Studi Arsitektur UK Petra, Ibu Eunike Kristi Julistiono, S.T., M.Des.Sc.

- Tim Desain Tahap I KKP Desain Inklusi: Ruth Liana Fransisca, Novia Oliviani Salim, Tiffany Ariana Kusuma, Laurentia Angel Stephanie, Jimmy Effendy dan Rezky Andi Saputra,

- Pimpinan Paguyuban Warga Strenkali Surabaya, Bapak Warsito dan Bapak Gatot Subroto

- Restoran Bandar Djakarta, Surabaya.

- PKL Makanan Laut di Kampung Tepi Sungai Surabaya

\section{DAFTAR PUSTAKA}

Ardiana, I.D.K.R., Brahmayanti, I.A., \& Subaedi, Subaedi, (2010), Small and Medium Economic Unit's Competency and Its Influence to Small and Medium Economic Unit's Effectiveness in Surabaya, (in Indonesian: Kompetensi SDM UKM dan Pengaruhnya Terhadap Kinerja UKM di Surabaya), Journal of Management and Entrepreneurship, Vol 12, no 1, March 2010,pp 42-55 accessed in http:/puslit2.petra. ac.id/ejournal/index.php/man/article/view/17988

Biro Pusat Statistik Indonesia (2004), Banyaknya Pekerja Usaha Tidak Berbadan Hukum Menurut Lapangan Usaha, 1996-2004, http://www. bps.go.id/tab_sub/view.php?kat=2\&tabel=1\& daftar=1\&id_subyek=35\&notab=3

Biro Pusat Statistik Indonesia (2004), Banyaknya Usaha yang Tidak Berbadan Hukum Menurut Lapangan Usaha 1996-2004, http://www.bps. go.id/tab_sub/view.php?kat=2\&tabel=1\&daftar $=$ \&id_subyek $=35 \&$ notab $=1$

http://rujak.org/2013/07/penataan-pkl-solo-bandungsurabaya-dan-bangkok/

http://undk.asia/

http://unitedboard.org/

http://www- edc.eng.cam.ac.uk / betterdesign /

http://www.kabarbisnis.com/read/2836424

Ormerod, M., \& Newton, R., (2003), The Application of Research Theory to Provide Widened Access for Students with Disabilities Through a Virtual Learning Environment, Best Practices in Building Education: HEFCE.

Sanoff, H. (1991). Visual Research Methods in Design. Department of Architecture, School of Design and Environment, North Carolina University, New York: Van Nostrand Reinhold

Shirvani, H, (1985), Urban Design Process, Van Nostrand Reinhold Company, New York.

Susanto, D. \& Suparlan, P. (1989). Keanekaragaman Makanan Pokok di Indonesia dan Ketahanan Sosial Budaya.Dalam Widyakarya Pangan dan Gizi. Jakarta: LIPI.

Tanuwidjaja, Gunawan, (2014), Desain Rumah untuk Hidup yang Bermartabat (Living in Dignity Home Design), Program Studi Arsitektur, Universitas Kristen Petra, Surabaya. 
Utami, R.M., \& Lantu, D.C., (February 2014), Development Competitiveness Model for SmallMedium Enterprises among the Creative Industry in Bandung, Procedia - Social and Behavioral Sciences, 115(21), pp. 305-323, The $5^{\text {th }}$ Indonesia International Conference on Inno- vation, Entrepreneurship, and Small Business (IICIES 2013), accessed in: http://www.sciencedirect.com/science/article/pii/S1877042814019867 Wirosardjono, S., (1976), Masalah Tenaga Kerja di Sektor Informal, Prisma V-9, Jakarta. 